\title{
Genealogía y trayectoria artesanal del queso criollo en hoja de luna de Hidalgo, México
}

\author{
Fernando Cervantes Escoto ${ }^{a^{*}}$ \\ María Isabel Palacios Rangel ${ }^{\text {a }}$ \\ Griselda Monroy Neria ${ }^{\text {a }}$ \\ Alfredo Cesín Vargas ${ }^{b}$ \\ Abraham Villegas de Gante ${ }^{\text {a }}$
}

${ }^{a}$ Universidad Autónoma Chapingo. Centro de Investigaciones Económicas Sociales y Tecnológicas de la Agroindustria y Agricultura Mundial, Chapingo, Estado de México. México.

${ }^{\mathrm{b}}$ Universidad Nacional Autónoma de México. México.

*Autor de correspondencia: tartalian04@gmail.com

\section{Resumen:}

El objetivo fue aportar información cualitativa sobre el queso criollo en hoja de luna, para contribuir a difundir su presencia y posibilitar su valorización y permanencia como acervo gastronómico local. En metodología, se aplicó una encuesta estructurada a 18 productores de queso, lo cual cubrió el universo total de personas dedicadas a esta actividad. También se realizaron entrevistas focalizadas de tipo semiestructurado con personajes clave, como las personas más antiguas que todavia lo elaboran, y los comercializadores. Además, se utilizaron las herramientas metodológicas de historia oral, método genealógico y trayectoria tecnológica. Se encontró que tiene un alto grado de artesanalidad, la técnica del saber-hacer asociado para su elaboración es la misma que utilizaban los ancestros de los productores, con mínimas modificaciones en su proceso. Se concluye, que se puede contribuir a su difusión y valorización como acervo gastronómico local, mencionando al consumidor, que 
este queso a pesar del tiempo ha conservado un carácter altamente artesanal; y que las peculiaridades que ha adquirido del entorno físico y cultural, se expresan en un sabor característico, mayor contenido graso, diferente coloración y consistencia; y que todo ello, junto con su envasado en la hoja de luna; le confiere características organolépticas diferentes a los quesos comerciales, y contribuye a generar un queso típico, con atributos valorados en la región en que se produce.

Palabras clave: Queso criollo, Historia oral, Método genealógico, Trayectoria tecnológica, Artesanalidad, Tipicidad.

Recibido: 11/09/2019

Aceptado: 03/06/2020

\section{Introducción}

Los alimentos son un componente importante en la identidad de la sociedad, en un mundo sometido a rápidos y profundos cambios, en el cual resulta importante destacar su papel, ya que ellos constituyen una referencia identitaria esencial ${ }^{(1)}$, donde las especialidades culinarias se han convertido en vínculo de acercamiento cultural, en la medida en que se han configurado como elementos que hablan de la vida de pueblos y territorios. La gastronomía puede convertirse entonces, en un elemento de sostenibilidad que mejore el buen vivir de la población que los produce, consume y comercializa ${ }^{(2)}$. En ese sentido, lo que la gente come, y como lo hace, puede convertirse en un elemento dinamizador de su cultura, que posibilita establecer pautas espacio-temporales y de forma, que a la larga se transforman no solo en hábitos alimenticios sino también en cultura tecnológica $\operatorname{alimentaria}^{(3)}$.

La sociedad enfrenta un escenario complejo, por la enorme riqueza simbólica y material implicada en la diversidad alimentaria y gastronomía local de los pueblos, aspecto que requiere ser visibilizado, debido a que no solo representa un acervo invaluable, sino que también forma parte de la memoria colectiva de la sociedad en su conjunto ${ }^{(4)}$.

El proceso de transformación industrial de los alimentos, genera un cambio en los patrones

de consumo, ya que sustituye los alimentos cotidianos, por el empleo indistinto de ingredientes altamente procesados. Este también es el caso de los quesos, cuya presencia a lo largo de la historia, muestra la capacidad que tenían los lugareños para elaborar un producto gastronómico con características, al mismo tiempo, propias y distintivas con 
respecto a los de otras regiones, pero que al insertarse en el dominio de la producción masiva tienden a perder sus vínculos territoriales, mismos que les generaban atributos especiales desde una visión social ${ }^{(5,6)}$.

En ese sentido, la producción masiva de quesos de imitación (aquellos elaborados con sucedáneos de leche) distorsiona la visión que los pueblos habían conservado de sus atributos de genuinidad y autenticidad comunitaria, al afectar su condición culinaria. Es decir, al poner a su alcance nuevos tipos de queso, cuyos componentes intrínsecos guardan escasa identidad con los procedimientos, utensilios e ingredientes originarios que les dieron su sentido comunitario, se abre la puerta para que se pierda, así como el conocimiento tácito (territorial, cultural y funcional) que llevaba implícita su elaboración ${ }^{(7,8)}$. Es decir, en este proceso, algunos quesos han ido perdiendo paulatinamente, parte de su saber-hacer, lo que representa en los hechos, la desaparición de una cultura tecnológica recreada a lo largo de siglos, lo que no es poca cosa; dado que el desarrollo local rural suele tener como base de sustento una actividad productiva de referencia, el concepto de producto agroalimentario local ${ }^{(9)}$, definido como aquel que emerge del acervo de saberes y recursos que constituyen un sistema agroalimentario localizado $(\mathrm{SIAL})^{(10)}$, se vuelve muy importante para esta investigación $^{(9)}$.

Así, la industrialización masiva y la elaboración creciente de productos sustitutos de los alimentos originarios, se ha convertido en factor determinante para la generación de un consumidor que desconoce, en su gran mayoría, las propiedades nutricionales y organolépticas contenidas por ejemplo, en los quesos genuinos, lo que se traduce, en los hechos, en una apreciación insuficiente del valor contenido en ellos, lo que afecta su presencia en mercados de alto consumo, convirtiéndolos en productos confinados, casi siempre, a espacios locales muy específicos ${ }^{(8,11)}$.

En México, existen cerca de 40 variedades identificadas como quesos artesanales genuinos, que enfrentan una gradual desaparición ${ }^{(12)}$, este es el caso del queso criollo en hoja de luna, un producto poco conocido que se elabora en la sierra alta del estado de Hidalgo. Es un queso fresco de consistencia blanda, se vende directamente al consumidor y solo se produce en esa región, donde las características del territorio, el tipo de ganado y el saber-hacer transgeneracional le otorgan particularidades que lo hacen único. Por tal motivo, es objetivo de este artículo es aportar información cualitativa sobre este queso, para contribuir a difundir su presencia y posibilitar su valorización y permanencia como acervo gastronómico local. 


\section{Material y métodos}

\section{Estrategias de recolección de datos y herramientas de análisis}

La investigación de campo se desarrolló durante el verano de 2018. Se aplicó una encuesta estructurada a 18 productores de queso, lo cual cubrió el universo total de personas dedicadas a esta actividad, que se ubican en la Sierra Alta del estado de Hidalgo, México, en los municipios de Molango de Escamilla y Lolotla (Figura 1). En el cuestionario, se incluyeron items que tenían como propósito identificar los elementos externos básicos, que determinan la preservación o no, de este queso en la región. Se utilizaron variables como: i) género, ii) edad, iii) escolaridad de quienes lo producen, iv) escala, v) uso de ciertas tecnologías, vi) existencia de otras actividades asociadas (producción de leche, comercialización, gestión de apoyos). De lo anterior se pudo identificar que género, escala de producción y uso de cierta tecnología eran las tres variables principales para entender el sistema quesero.

Figura 1: Municipios en los que se produce el queso criollo en hoja de luna

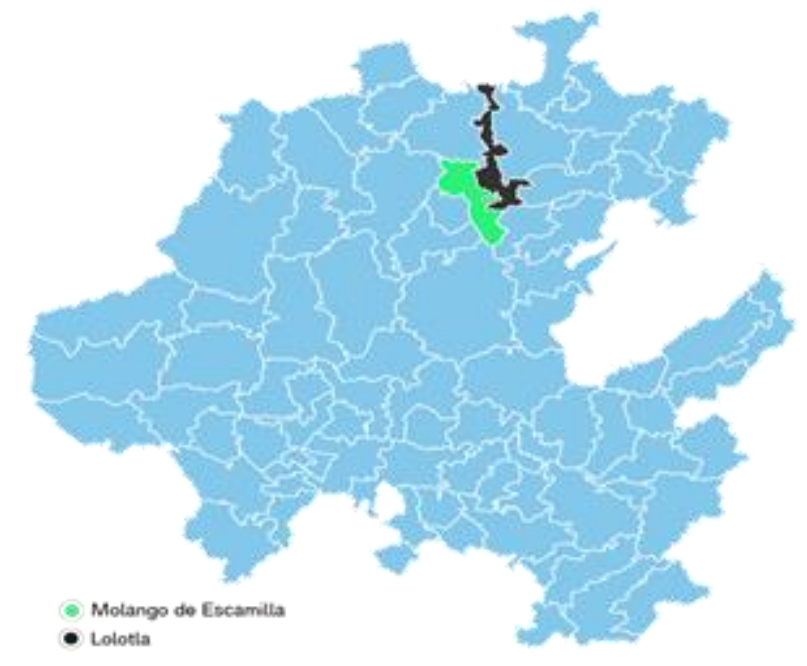

También se realizaron entrevistas focalizadas de tipo semiestructurado con personajes clave, como las personas más antiguas que todavia lo elaboran, y los comercializadores. Cabe señalar que se eligió este tipo de técnica cualitativa, porque resultó ser adecuada, dado el interés particular en profundizar sobre determinados aspectos ${ }^{(13)}$. Para el caso concreto, las preguntas tenian que ver con aspectos tales como: i) origen de la producción del queso en la región, ii) existencia de lazos de filiación o no entre quienes han preservado su hechura; iii) canales o medios mediante los cuales se transfirió y preservó el saber-hacer; iv) elementos tecnológicos del saber-hacer (saberes, tradiciones, equipo, instrumentos e 
insumos) preservados o desaparecidos a través del tiempo; v) dinámica y vínculos entre los elementos que integran el sistema; vi) niveles de estabilidad o inestabilidad entre los distintos elementos básicos para la producción del queso. Para el caso, se consideró como un factor de estabilidad o inestabilidad, la presencia o no, de cambios tecnológicos en el tiempo, aspecto que se contempló como que le confiere valor agregado al producto.

Para seleccionar a las personas a quienes se les aplicaría la encuesta y se les haría la entrevista, se utilizó el método muestral no probabilístico, conocido como "Bola de nieve discriminatorio exponencial"(14), que consiste en ir preguntando a residentes del lugar, quienes son los individuos o grupos con un conocimiento especial del fenómeno a investigar; a medida que se avanza se recoge un conjunto de recursos ricos en información ${ }^{(15)}$. Al final se logró un censo de todos los que se dedican a la actividad, 18 queseros.

Como parte de las herramientas metodológicas se empleó la historia oral, la cual ofrece una alternativa dinámica y sencilla para identificar el valor simbólico que tienen algunos productos agroalimentarios para los habitantes de las comunidades, y determinar si son considerados un legado de los antepasados ${ }^{(16)}$. En este caso, se utilizó para identificar el origen del queso criollo en hoja de luna, a través de la memoria y el relato de los productores (la hoja de luna pertenece al género Xanthosoma; se le conoce comúnmente también como mafafa, otoe, malanga, cocoñame). También se utilizó el método genealógico, para indagar sobre el saber-hacer quesero, el cual permitió visualizar la transferencia del conocimiento del queso a través de las generaciones de las familias productoras. Esta información se sistematizó y representó gráficamente en genealogías ${ }^{(17)}$.

Por lo general, este método se emplea en investigaciones de corte antropológico, ya que posibilita entender toda una gama de aspectos (sistemas de parentesco, leyes y normas de la filiación y herencia, migración, magia, religión, usos y costumbres), todos vinculados con el comportamiento social y cultural, individual o grupal, en ciertos entornos societarios. De igual manera, se utiliza para reconstruir las relaciones de parentesco establecidas al interior de un grupo, así como la historia comunitaria y familiar en la cual se inscribe. También se emplea cuando se requiere hacer un análisis más detallado de los sistemas de producción. Es de particular utilidad cuando se quiere estudiar el desarrollo de la quesería artesanal, como este caso ${ }^{(16)}$.

Otra herramienta metodológica que se utilizó fue el enfoque de la trayectoria tecnológica, con el cual se buscó identificar los cambios tecnológicos que se han incorporado a las unidades de producción a través del tiempo, para verificar el grado de persistencia de la "tradición tecnológica" en la elaboración de los productos agroalimentarios, mediante la evaluación de los efectos que han tenido en la preservación o pérdida de la genuinidad ${ }^{(18)}$. Se verificaron los cambios en las etapas del proceso, uso de insumos y equipo para la 
producción del queso criollo. Para identificar la trayectoria tecnológica del queso, se consideraron las variables volumen de leche procesado, uso de instrumentos y equipos para la elaboración, empleo de insumos relacionados con la producción (leche fluida y/o en polvo, cuajo animal y/o sintético, cloruro de calcio) y realización de pruebas de calidad. En el Cuadro 1 se relacionan todas las variables y herramientas utilizadas.

Cuadro 1: Variables y herramientas utilizadas

\begin{tabular}{|c|c|}
\hline Variable & Herramienta \\
\hline \multicolumn{2}{|l|}{ Datos generales } \\
\hline Género & Encuesta, entrevista focal \\
\hline Edad & Encuesta, entrevista focal \\
\hline Escolaridad & Encuesta, entrevisa focal \\
\hline Familiares dedicados a la actividad & Entrevista focal \\
\hline \multicolumn{2}{|l|}{ Historia oral } \\
\hline Antigüedad del queso & Entrevista focal \\
\hline Primera persona que lo produjo & Entrevista focal \\
\hline Contexto del evento & Entrevista focal \\
\hline Cómo se difundió el saber-hacer & Entrevista focal \\
\hline \multicolumn{2}{|l|}{ Genealogía } \\
\hline Familiar más antiguo dedicado a la actividad & Entrevista focal \\
\hline $\begin{array}{l}\text { Conocidos dedicados a la actividad (no } \\
\text { familiar) }\end{array}$ & Entrevista focal \\
\hline De quién aprendió & Entrevista focal \\
\hline A quién le enseñó & Entrevista focal \\
\hline Años dedicados a la actividad & Encuesta, entrevista focal \\
\hline \multicolumn{2}{|l|}{ Trayectoria tecnológica } \\
\hline Uso de cierta tecnología & Encuesta \\
\hline Volumen de leche procesada & Encuesta \\
\hline $\begin{array}{l}\text { Maquinaria, equipo, instrumentos para el } \\
\text { proceso de elaboración }\end{array}$ & Encuesta \\
\hline Uso de insumos & Encuesta \\
\hline \multicolumn{2}{|l|}{ Pruebas de calidad } \\
\hline Escala de producción & Encuesta \\
\hline Cambios en el proceso de elaboración & Encuesta \\
\hline \multicolumn{2}{|l|}{ Comercialización } \\
\hline Quién lo vende & Encuesta, entrevista focal \\
\hline A quién se le vende & Encuesta, entrevista focal \\
\hline Empaque & Encuesta \\
\hline Lugar de venta & Encuesta \\
\hline Distancia del punto de venta & Encuesta \\
\hline
\end{tabular}




\section{Resultados y discusión}

\section{Origen del queso criollo en hoja de luna}

La elaboración de este queso inició en varias comunidades de los municipios de Molango y Lolotla hace aproximadamente un siglo. La interpretación etimológica de la palabra Molango es "Lugar de Mole", denominación, de raíz náhuatl, que le dieron los aztecas al conquistar la región. Lolotla, también palabra náhuatl, significa "piedra rodeada de hilo", expresión que hace referencia a la topografía del lugar, constituida por lomeríos donde se asientan la mayoría de las viviendas. De acuerdo con los resultados obtenidos mediante la historia oral, el queso criollo en hoja de luna se empezó a elaborar alrededor de 1916 por la familia Melo Quijano. En su narración de hechos, uno de sus descendientes, el Sr. Ángelo Crescenciano Melo Castillo, rememora que sus abuelos eran dueños de una amplia extensión de terreno, y poseían alrededor de 130 cabezas de ganado bovino, el cual, como ahora, era criado en el monte (elevación natural de terreno cubierta de vegetación).

Para la ordeña los peones se trasladaban caminando hasta el monte, cargando sobre la cabeza un chapal, olla de barro con capacidad de hasta 20 L, que servía para almacenar la leche durante su traslado; para evitar lastimarse con el peso, lo cargaban en la cabeza con el apoyo de un trapo que se entretejía. Una vez realizada la colecta de leche, la llevaban hasta la cocina de doña Rafaela Pedraza Bautista, esposa de Delfino Melo Quijano, propietario de la finca. Después de que se consumía, o vendía, el líquido fresco, con los excedentes se elaboraba el queso criollo. Una vez en la cocina, la leche se vaciaba en otro chapal de barro, colocando una manta para colarla, para evitar la proliferación de agentes extraños, que pudieran descomponerla o trasmitirle sabores desagradables al queso. Si la leche aún se encontraba caliente le adicionaban cuajo natural, pero si no, se calentaba en el fogón hasta que alcanzara una temperatura aproximada de 37 a $38^{\circ} \mathrm{C}$, se agregaba el cuajo y se dejaba reposar. Una vez formada la cuajada, ésta se cortaba con un chamolito, palo en forma de cruz, para después, con las manos, irla separando poco a poco dentro del mismo chapal, hasta formar una bola que se extraía y colocaba sobre una manta, y así hasta terminar. Una vez separado el suero de la cuajada se molía en el metate agregando poco a poco sal. Después, se formaban las piezas en moldes de madera, donde se escurrian colocados sobre una tabla inclinada, posteriormente se envolvía cada pieza en la "hoja de luna" (planta que abunda en la región), contribuyendo a su conservación y a la preservación de sus cualidades organolépticas. 


\section{Características del sistema quesero local}

\section{La comercialización del queso}

Se hacía de forma directa con el consumidor y se realizaba en algunas poblaciones vecinas como Zacualtipán, Tamazunchale, San Felipe, Huitepec, e Ixtlahuaco. Era tan demandado que, según los informantes, tardaban más en llegar al sitio que en venderse; además del queso, ofrecían leche y requesón. Se ha documentado que algunos productos, como el queso, se venden mejor si tienen el reconocimiento del consumidor ${ }^{(19)}$; además, la confianza en la calidad del alimento se establece, entre otros parámetros, por las relaciones personales entre el productor-comercializador y el consumidor y las recomendaciones de boca en boca, buenas o malas, contribuyen a la construcción del prestigio del quesero artesanal, para el caso que nos ocupa. En ese sentido, en los mercados locales es importante para el comerciante la fidelidad de los consumidores, la cual se construye con constancia, cuidando todo aquello que constituye una relación armónica y por periodos prolongados, pero se puede perder rápidamente. En ese nivel, es importante que los dos sujetos que intervienen en la transacción consideren que salen beneficiados de ella.

Como sucedía en todo el país en esa época, para el transporte de los productos se utilizaban animales de carga, ya sea caballos, burros o mulas. El traslado del queso y del requesón se hacía en "chiquigüites", vocablo de origen náhuatl, con el que se nombra a canastos de mimbre, de diversos tamaños, hechos de varas raspadas, para el caso de la leche, usaban chapales. No todo el queso producido se enviaba al mercado, una parte importante se comercializaba en la casa. De manera similar, en el caso del queso serrano de Campos da Cima do Serra (Brasil), a mediados del siglo XVIII, las caravanas de mulas transportaban el queso desde la localidad en que se elaboraba hasta el vecino estado de Santa Catarina, donde se comercializaba y difundía el gusto por el producto $^{(20)}$.

Similar a esta la forma de comercialización, era la del queso Cotija, que era transportado por arrieros, como producto y tambien como alimento, desde el occidente mexicano hasta el sureste del país, incluso se menciona que llegaba a algunas partes de Centroamérica, teniendo como consecuencia que actualmente se elabore un queso tipo Cotija en el estado de Chiapas, resultado de la transmisión del saber hacer y la migración de productores derivada de esos intercambios iniciales.

En el caso del queso en hoja de luna, la forma de pago era diversa, en algunos casos se hacía mediante transacción monetaria, en otros, por trueque, o, incluso, a cambio de algún trabajo realizado por al adquiriente. Debido a que se producía en el ámbito doméstico y de forma artesanal, la cantidad de pedidos era pequeña, como máximo 20 piezas, lo cual hace 
referencia no solo a su pequeña escala de producción, sino también a que había personas que compraban todo lo producido, haciendo hincapié en la calidad del producto. Esto es similar en algunas localidades cercanas al mediterráneo italiano, en donde una cantidad importante de quesos artesanales poseían un sabor único y peculiar, siendo la mayoría elaborados como quesos de granja, producidos a partir de leche cruda ${ }^{(21)}$. En el mismo sentido, algunos autores mencionan que esto se debe, especialmente, a que cuando las características únicas de un producto, como el queso, satisfacen al cliente, la demanda tiende a guardar fidelidad al producto, al mismo tiempo que crece $^{(22)}$.

\section{La necesidad de valorizar el queso en hoja de luna}

En el momento de la investigación, la venta de leche cruda en la región era mínima, los queseros señalaron que aproximadamente en 1996 se introdujo en los comercios locales el lacticinio en envase de cartón, lo cual disminuyó hasta su desaparición la demanda de leche cruda. Desde entonces, el total de la leche producida, en esas comunidades, se procesa para transformarla en queso, el cual sigue teniendo buena fama y aceptación en la zona. Lo anterior, se sostiene, como es el caso del queso en hoja de luna, en que los quesos artesanales poseen una fuerte raíz comunitaria y local, debido a que su elaboración se basa, desde sus orígenes, en la utilización de recursos naturales y sociales autóctonos, facilitando su integración en la cultura gastronómica local.

Cuando la problemática de los quesos artesanales trasciende lo local, por los diferentes fenómenos que se han presentado en el medio rural, tales como pérdida de población, por migración, y por la misma razón, el riesgo de que desaparezca el conocimiento tradicional vinculado con el saber hacer, el aumento de los indices de pobreza, etc.; se vuelve necesario valorizarlos, porque con ello se contribuye al desarrollo de las comunidades y de los queseros, y se asegura su permanencia en la actividad, ya que un alimento tradicional es un producto consumido frecuentemente o asociado a celebraciones o épocas del año específicas, temporada de lluvias por ejemplo, normalmente es transmitido de generación en generación, elaborado con esmero de una forma concreta (saber-hacer), según la herencia gastronómica, con poco o ningún procesado/manufacturado, diferenciado y conocido por sus propiedades sensoriales y asociado con una localidad, región o país determinado, por lo tanto merece ser preservado o rescatado, según sea su situación ${ }^{(23)}$.

Finalmente, un aspecto por demás importante en la valorización territorial de los quesos artesanales es la implementación de protocolos, en las queserías, para asegurar la calidad sanitaria del producto, asimismo, otro tipo de atributos como los organolépticos, son los que le proprcionan fortalezas a este tipo de alimentos. Por otro lado, se debe garantizar un adecuado manejo y conservación de los recursos naturales locales, así como, incentivar la participación de los productores para lograr los objetivos señalados ${ }^{(11)}$. Un ejemplo de esto se relaciona con la elaboración del queso Cotija en México, cuyos productores formularon 
el proyecto "Potencialización del patrimonio cultural de la sierra de Jalmich", lo que permitió involucrar a todos los actores y hacer coincidir la mejora de su calidad alimenticia y artesanal con el rescate de éste como patrimonio colectivo (económico, social y cultural ${ }^{(24)}$. Otro caso lo constituyó el queso bola de Ocosingo, Chiapas, México, donde los productores lograron la consecución temporal de una marca colectiva (MC), que le dio durante un periodo considerable de tiempo, reconocimiento externo a la cultura quesera local ${ }^{(25)}$. En estos dos casos, cuando los productores consideraron que no tenían la misma problemática o afloraron los desacuerdos, los procesos de valorización fracasaron, ya sea disolviéndose la organización o siendo apropiada por unos cuantos actores, excluyendo a los demás miembros originales.

Sin embargo, revalorizar la cultura quesera local requiere desarrollar diversas acciones, la mayoría de ellas colectivas, que muchas veces los productores no logran consolidar, como son organizarse para lograr el bien colectivo, y de esta forma mejorar aspectos tales como, la calidad sanitaria del queso y su proceso productivo, su control de calidad, la certificación del producto, además del desarrollo de mejores opciones de mercado. Hay que considerar que una indicación geográfica (IG), o cualquier otro sello de anclaje territorial, no tienen valor por sí mismo, sino se sustentan en la acción colectiva, de los productores y demás actores cercanos, que influyen en la elaboración de los quesos tradicionales, genuinos y de identidad social ${ }^{(25)}$.

Cabe señalar que los consumidores no siempre valoran factores de tipo intangible (reconocimiento, cultura) que incidan sobre su consumo. Por tanto, es un aspecto importante que debe rescatarse de los quesos artesanales, su riqueza cultural a fin de generar una mayor valoración por parte del consumidor ${ }^{(26)}$. La revalorización de productos locales se ha constituido como una estrategia que se encuentra íntimamente relacionada con lo que muchos autores denominan desarrollo local, presentando una concepción del desarrollo como algo generado a partir de las capacidades y recursos locales ${ }^{(10)}$.

\section{La transmisión del saber-hacer del queso criollo en hoja de luna a través de generaciones}

A partir de diversos relatos de los descendientes del Sr. Delfino Melo Quijano, se generó la pauta que permitió ubicar el origen del queso en hoja de luna, así como la forma en que el saber-hacer se fue transmitiendo de una generación a otra. Así se logró interconectar la transferencia de conocimiento con la elaboración del producto. La narración oral refiere: "al contar Don Delfino y su esposa Rafaela Pedraza con una gran cantidad de ganado, decidieron producir queso con el remanente que les quedaba después de la venta de leche bronca". De esta forma "mientras Delfino y algunos empleados se encargaban del cuidado de las vacas y la ordeña, Rafaela elaboraba el queso en casa, apoyada por algunas vecinas, 
ya que como es tradición, a la par de sus actividades domésticas y la atención que prestaba a sus cinco hijos: Gonzalo, Casimiro, Pablo, Baldomero y Sofía, sus preocupaciones también se orientaban a obtener un poco más de recursos pecuniarios". Un hecho innegable es que "la producción de queso con el tiempo no solo integró a las mujeres de la familia, sino de igual modo a los hombres". El saber-hacer fue trasmitido a todos. Sin embargo, solo algunos de los hijos continuaron con la actividad.

Andrea Castillo esposa de Casimiro Melo Pedraza, aprendió de su suegra la técnica quesera. Ella se convirtió, con el paso del tiempo, en una colaboradora importante en la hechura del queso. Del matrimonio Melo Castillo nacieron seis hijos, dos hombres y cuatro mujeres, cuyos nombres fueron Ángelo Crescenciano, Crisanto, Justina, Teresa, Prisca y Honorina, de todos fue Ángelo Crecenciano en compañía de su esposa, Angelina Díaz Hernández, el que rescató el saber-hacer quesero, conocimiento que heredaron a su vez sus dos hijas, Griselda y Susana, las que también aprendieron el proceso de elaboración desde que eran pequeñas. Por su parte, Honorina, hija menor de Casimiro Melo Pedraza y Andrea Castillo, contrajo matrimonio con Rodolfo García Díaz, pequeño ganadero local, el que no sólo sigue aportado el insumo lácteo, base para la producción del queso, sino que también ha estimulado que ella siga elaborándolo en la actualidad. Este saber lo ha transmitido a sus hijos, Alejandro y María Concepción, quienes, aunque pequeños todavía, han aprendido la técnica, y seguramente serán ellos los que con el tiempo continúen con la tradición quesera familiar.

Cabe destacar que, en esta región la mayoría de los queseros actuales, siguen preservando la forma tradicional en que la familia originaria elaboraba este tipo de queso. Tal es el caso de Paula y Graciela Hernández, Cipriana López, Irma Reyes, Cecilia Apolonio, Marina Bustos, Alicia e Hilaria Montiel y la familia Campoy, quienes en su testimonio mencionan que sus padres o abuelos, trabajaron muy cercanamente en la producción con Rafaela Pedraza. De esta forma se puede decir que el conocimiento y técnica de elaboración del queso criollo en hoja de luna, ha rebasado el círculo familiar que le dio origen, y se han transformado en un valor comunitario. En la Figura 2, se describe la simbología utilizada en el mapa genealógico que integra, a los actores que han intervenido, a partir de la familia Melo Pedraza, en la preservación del conocimiento y técnica para la elaboración del queso criollo en hoja de luna en esta región, y la Figura 3 muestra la genealogía seguida para la difusión del conocimiento en la elaboración del queso criollo, por aquellas personas que lo aprendieron directamente de esa familia. 
Figura 2: Simbología utilizada en el mapa genealógico

Persona que recupera la tradición quesera

Figura 3: Genealogía de la difusión del conocimiento de la elaboración del queso criollo

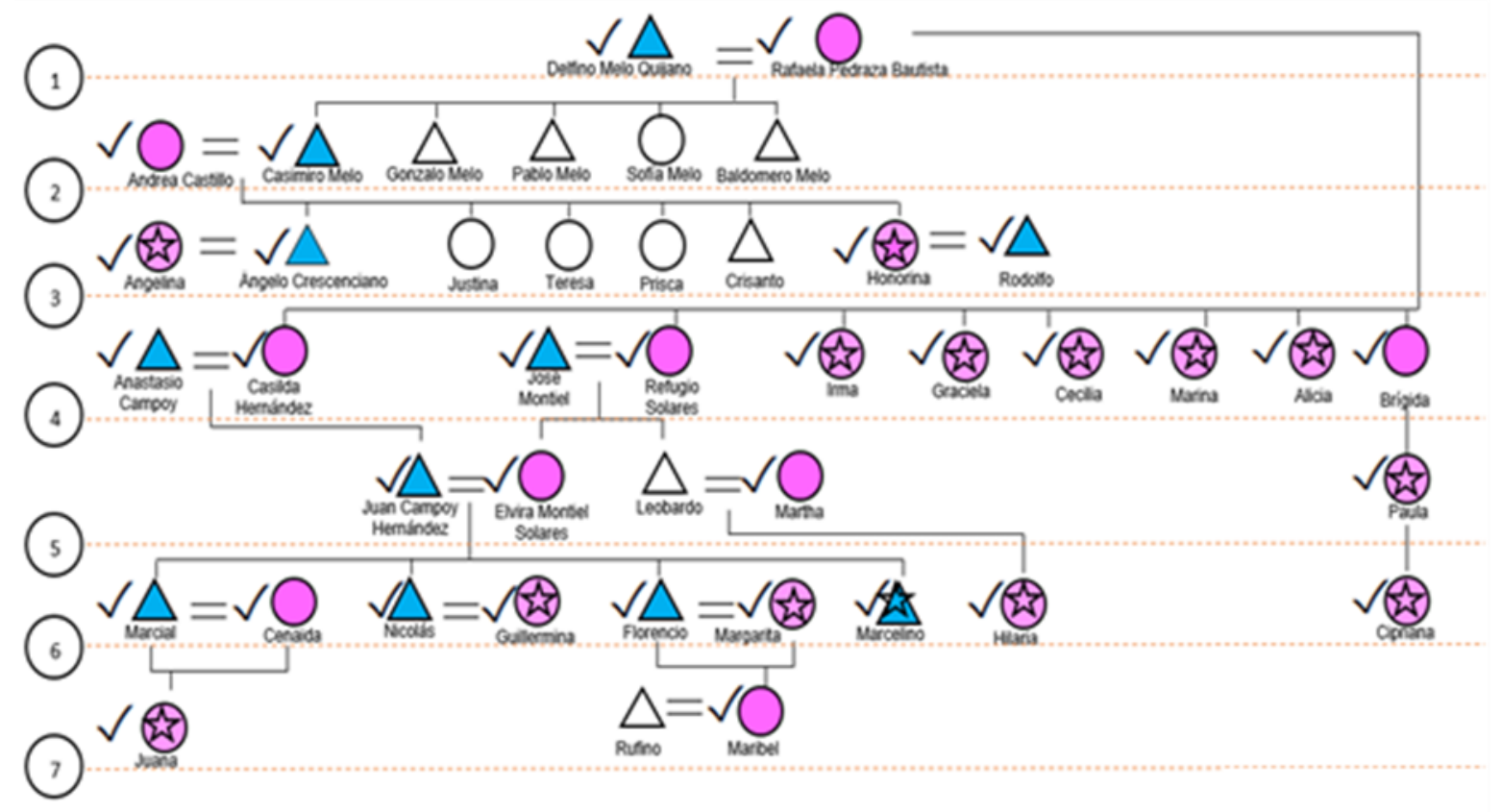

Existen otras vertientes mediante las cuales se desarrolló la transmisión del saber-hacer quesero, pero que no se relacionan de forma directa con la familia Melo Quijano, lo cual puede interpretarse como que la cultura, en la producción de este acervo culinario, tiene orígenes internos muy precisos, pero también ramificaciones externas, que se relacionan con el desarrollo de la producción del mismo, como parte de un sistema geográfico más 
amplio $^{(27,28)}$. Este es el caso de la Sra. María del Carmen Bustos, quien acumula más de 40 años de experiencia en la actividad, misma que le fue enseñada por su mamá, Lucía Pelcastre, quien a su vez la aprendió de su abuela, Rufina Apolonio, desarrollando juntas la actividad hasta el fallecimiento de la última. Un caso similar es el de la Sra. María Abraham Ávalos, la que se dedica a elaborar este queso desde hace 37 años, conocimiento que adquirió de su suegra, Teresa Mendoza. De igual forma, Raúl Valentín, quien desde hace desde cinco años produce el queso, técnica que le enseñó su abuela Agustina Serna. También, el testimonio de Abundia Juárez, quien adquirió el saber de su madre; ambas lo elaboran desde hace treinta años. En la Figura 4, se representa el mapa genealógico de estos queseros.

Figura 4: Genealogía de las familias donde no se logró establecer la transferencia de conocimiento de la producción de queso criollo

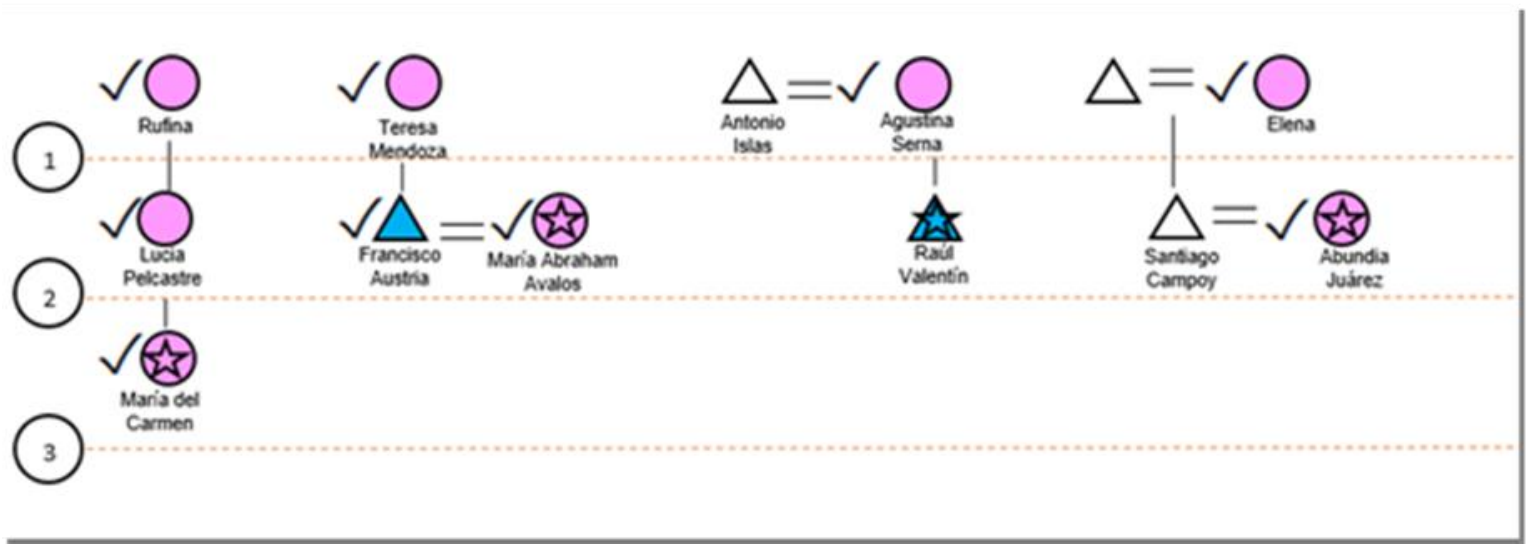

Como se observa, desde los testimonios aportados, la participación de las mujeres en la transmisión del saber-hacer para la elaboración de este producto ha sido predominante. Sin embargo, la permanencia de la práctica quesera en esta región es un factor que, aunque marca de manera clara la presencia femenina en su fabricación, al mismo tiempo, forma parte de una estrategia de reproducción familiar, ya que en su manufactura se involucra a todo el núcleo. De esta forma hay una división de las actividades, el padre se encarga de la producción de leche y del mantenimiento de las vacas; la mujer elabora, difunde el saberhacer y vende el queso; los hijos e hijas colaboran en su producción y distribución; es decir, el queso criollo en hoja de luna no solo tiene un sabor territorial, sino también forma parte de una cultura familiar que trasciende el ámbito doméstico, y se convierte en un factor geográfico de identificación comunitaria.

Así, el hecho de que la producción de queso complemente los ingresos familiares, al integrar las actividades de la madre con la quesería, y que todo esto cuente con el apoyo activo de los integrantes de la familia, son factores que han ayudado al sostenimiento de su producción. Investigaciones previas apuntan a que la estructura doméstica que está detrás de la producción de queso en pequeñas unidades familiares es resultado de adecuaciones a 
la división familiar del trabajo, misma que se modifica a medida que la mujer tiene una participación económica más amplia en la captación del ingreso, lo que, también, repercute en un incremento sustancial de su producción ${ }^{(29)}$. El este caso, la quesería es un ejemplo paradigmático del proceso de transición de una sociedad rural tradicional a la nueva ruralidad ${ }^{(30)}$, adaptación a nuevos escenarios que no es uniforme y que, para las regiones o actividades menos favorecidas representa un verdadero reto, con más limitantes que recursos para superarlo.

Del mismo modo, el estudio previo de un caso de producción de queso artesanal en Hezergovina, concluyó que la mujer desempeña un papel muy importante en la valorización de los productos típicos, lo cual garantiza no sólo su reconocimiento, protección y bienestar económico, sino también genera un modelo más integrado en el desarrollo de la región de origen, que muestra evidentes ventajas de mejora y beneficios tangibles (crecimiento del empleo, mayores ingresos, etc.) ${ }^{(31)}$. En otras regiones de México, la producción familiar de leche y la tradición en la fabricación de quesos, ha sustentado el desarrollo local de un territorio delimitado. En estos ámbitos, la articulación del sistema familiar de leche se convierte en un recurso productivo específico, vinculado a la fabricación doméstica, local y regional de quesos, donde el saber-hacer se transforma en una ventana de oportunidades, con fama y reputación regionales ${ }^{(32)}$. Esta articulación es importante, porque da viabilidad a hogares en el medio rural, integrando a los diferentes miembros de la familia a la actividad quesera, algunos de tiempo parcial y permitiendo la pluriactividad que puede ser fundamental para su funcionamiento.

Particularmente, la conservación del carácter artesanal de un producto es un proceso de producción y características que se definen en función de los saberes locales, e incluso de las prácticas culinarias heredadas por cada familia, este, representa una ventaja a lo largo de la cadena hasta el consumo final ${ }^{(33)}$. Las relaciones de confianza se establecen entre el productor (o comercializador) y el consumidor, pueden ser perdurables por mucho tiempo, los productos son valorados, recomendados y promocionados de boca en boca, por sus compradores, enalteciendo sus cualidades. En el caso particular del Queso Crema de Chiapas (QCCh) las características de producción artesanal son aquéllas que el sujeto valora y van de acuerdo al origen, la forma de producirse, los enseres de elaboración, el ganado que se utiliza (de doble propósito), su alimentación, el saber-hacer del queso (transmitido por generaciones), etc. y que al final contribuyen a impartir las características únicas al queso como son la genuinidad y tipicidad. Los queseros valoran el proceso ya que les permite reproducir su saber-hacer, transmitido en la historia; también les posibilita formar parte de un grupo o gremio, donde el conocimiento se comparte y mejora ${ }^{(34)}$.

En ese sentido, el saber-hacer de los productos artesanales está asociado a conocimientos empíricos que se difunden a manera de procesos de educación no formal, escasamente valorados por las instituciones públicas. Esta situación se asocia con la elaboración de 
productos de calidad ligada al origen, donde las condiciones climáticas naturales les confieren características distintivas que permiten a los consumidores su reconocimiento y valorización $^{(10)}$. De esta manera, el potencial creciente de este tipo de productos genuinos se vincula de forma estrecha con aspectos tales como, la diversidad geográfica y cultural, y posibilita la creación de una gran variedad de alimentos y formas de preparación en la gastronomía local y regional ${ }^{(35)}$.

\section{Trayectoria tecnológica en el proceso de elaboración del queso criollo en hoja de luna}

Al estudiar los productos típicos en Italia, como estrategia para fortalecer el turismo gastronómico, se considera que el grado de artesanalidad en la elaboración de un producto local está directamente vinculado con la relación entre territorio y producciones originales, y ésta contribuye a elevar la calidad del producto, por el cuidado que le ponen los productores en la selección de los ingredientes ${ }^{(36)}$. Lo anterior, también posibilita que el producto genuino conserve su pertenecía cultural, lo cual establece un vínculo fuerte entre el producto genuino y el desarrollo de una conciencia comunitaria valorativa.

El queso criollo en hoja de luna surgió, al igual que otros, como una estrategia para aprovechar los excedentes estacionales de leche. La manera de elaborarse en la actualidad sigue siendo muy similar a la original, sólo se han incorporado algunos cambios leves en el proceso (Cuadro 2). La mayor parte de los quesos mexicanos genuinos se comenzaron a elaborar en los ranchos como un medio para aprovechar y conservar los excedentes de leche en el periodo de lluvias.

Cuadro 2: Trayectoria tecnológica del sistema productivo de queso criollo en hoja de luna

\begin{tabular}{|c|c|c|}
\hline Año & Tecnología de elaboración & Imagen \\
\hline 1916 & Fecha que se estableció como la del origen de este queso. & \\
\hline 1917 & $\begin{array}{l}\text { En este año se terminó de concluir la designación del } \\
\text { procedimiento para la elaboración de este queso, mismo } \\
\text { que incluyó los siguientes aspectos: } \\
\text { - Para la elaboración se utilizaba leche fluida de vaca } \\
\text { - la leche se cuajaba en los chápales de barro, los } \\
\text { cuales tenían una capacidad de } 20 \text { litros; para tal } \\
\text { procedimiento se utilizaba el chamolito, }\end{array}$ & \\
\hline
\end{tabular}




\section{Año}

Tecnología de elaboración

Imagen

instrumento de palo semejante a una cuchara.

- La temperatura se determinaba con base en la observación y el tacto.

- El procedimiento de molido de la cuajada se realizaba en metate, en esta etapa de elaboración se le agregaba sal gruesa.

- El procedimiento de escurrido consistía en colocar el queso molido en una hoja de luna y ahí se dejaba el tiempo necesario para que adquiriese consistencia y sabor.

- Una vez logrado lo anterior se terminaba de envolver el queso en la hoja de luna, lo cual permitía su posterior traslado y venta.

- El procedimiento de elaboración del queso no incluía el uso de canastos de hoja de palma, ni de recipientes metálicos

1994 Se empieza a introducir en la elaboración del queso el garrafón de plástico y las cubetas de aluminio, utensilios que sustituyeron el uso del chápal.

1997 Se empieza a utilizar lienzos de tela o talegos para facilitar el escurrido del suero.

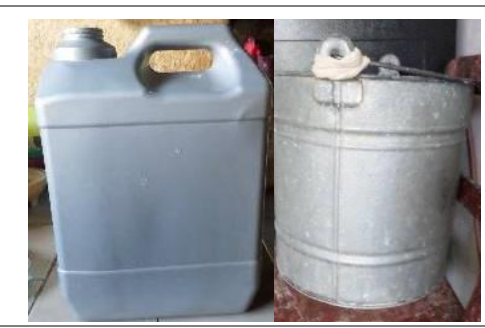
elescurrido delsuero.

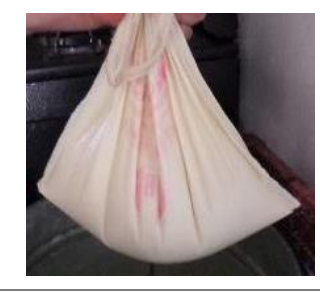

1998 Se sustituyó el uso del chamolito por la cuchara de aluminio, aunque en la actualidad todavía algunos queseros lo siguen utilizando (Por ejemplo, Angelina Díaz e Hilaria Apolonio).

1999 Se introdujo el uso de moldes de madera y PVC.

2012 Se sustituyó la utilización de cuajo natural por el comercial

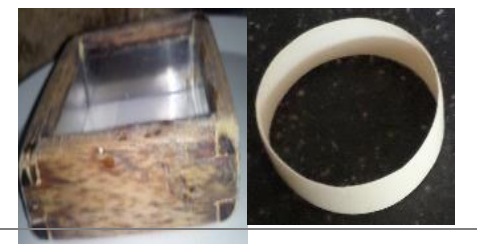




\begin{tabular}{|c|c|c|}
\hline Año & Tecnología de elaboración & Imagen \\
\hline & (solo dos productores). & \\
\hline 2013 & $\begin{array}{l}\text { El quesero Raúl Valentín sustituyó la hoja de luna por bolsas } \\
\text { de plástico, situación que no prosperó entre los otros } \\
\text { productores. }\end{array}$ & \\
\hline 2017 & $\begin{array}{l}\text { Del procedimiento tradicional en la elaboración de este } \\
\text { queso continua vigente, el empleo de leche fluida de vaca, } \\
\text { la forma de cuajado, salado y molido. Así como el envasado } \\
\text { del producto final en la hoja de luna. }\end{array}$ & \\
\hline & $\begin{array}{l}\text { La pasteurización de la leche no ha sido un método } \\
\text { adoptado por los queseros, dado que este procedimiento } \\
\text { adiciona costos al producto, además de modificar la } \\
\text { consistencia y sabor del queso. }\end{array}$ & \\
\hline
\end{tabular}

\section{Conclusiones e implicaciones}

El anclaje territorial (entendido como el vínculo que tienen los productos alimentarios, con el lugar donde se producen) resulta fundamental para entender y sostener un sistema artesanal como el que aquí se presenta, ya que esa conexión se transforma con el tiempo en una tradición culinaria, de la cual los pueblos se sienten altamente orgullos. La importancia del queso criollo en hoja de luna consiste en que es, precisamente, un alimento con historia, resultado de un saber-hacer propio, que ha sido transmitido por generaciones a través de familiares y conocidos. Una forma en que se podría contribuir a su difusión y valorización como acervo gastronómico local, sería mencionando al consumidor que este queso, a pesar del tiempo, ha conservado un carácter altamente artesanal, y que las peculiaridades que ha adquirido del entorno físico y cultural, se expresan en un sabor característico, mayor contenido graso, diferente coloración y consistencia; además, de su envasado en la hoja de luna; todo ello le confiere características organolépticas diferentes a los llamados quesos comerciales.

\section{Literatura citada:}

1. Muchnik J. Identidad territorial y calidad de los alimentos: procesos de calificación y competencias de los consumidores. Agroalimentaria 2006;(22):89-98.

2. Martín GMB, López AXA. Productos agroalimentarios de calidad y turismo en España: Estrategias para el desarrollo local. Geographicalia 2005;(47):87-110. 
3. Nunes DC. Somos lo que comemos Identidad cultural, hábitos alimenticios y turismo. Estud y Perspect en Tur 2007;16(2):234-242.

4. Unigarro SC. Patrimonio cultural alimentario. Primera ed. Ecuador: Auxiliadora Balladares UM, editor; 2010.

5. Leyva TDA, Pérez VA. Pérdida de las raíces culinarias por la transformación en la cultura alimentaria. Rev Mex Cienc Agríc 2015;6(4):867-881.

6. Fournier T. Are traditional foods and eating patterns really good for health? In: Sébastia B, editor. Comer comida tradicional Política, identidad y prácticas. 1rst ed. Francia: Routledge; 2016:180-200.

7. Bachmann HP. Cheese analogues: a review. Int Dairy J 2001;11(2001):505-515.

8. Cesín VA, Aliphat FM, Ramírez VB, Herrera HJG, Martínez CD. Ganadería lechera familiar y producción de queso. Estudio en tres comunidades del municipio de Tetlatlahuca en el estado de Tlaxcala, México. Téc Pecu Méx 2007;45(1):61-76.

9. Otero J. Valorización de productos agroalimentarios locales para el desarrollo rural: reflexiones sobre dos experiencias argentinas. Rev Agroaliment 2015;21(41):71-80.

10. Velarde I. Methodological Proposal for the activation of localized agroalimentary systems in Argentina. International Conference of Territorial Intelligence. Salermo, Italy. 2009:1-26.

11. Cervantes EF, Villegas GA, Cesín VA, Espinoza OA. Los quesos mexicanos genuinos. Patrimonio cultural que debe rescatarse. 2nd ed. Guadalajara: Colegio de Posgraduados, Universidad Autónoma Chapingo, Instituto Interamericano de Cooperación para la Agricultura, Grupo Mundi-Prensa; 2013.

12. Villegas GA, Cervantes EF. La genuinidad y tipicidad en la revalorización de los quesos artesanales mexicanos. Estud Soc 2011;19(38):147-164.

13. Merton RK, Fiske M, Kendall PL. Propósitos y criterios de la entrevista focalizada. Empiria Rev Metodol Ciencias Soc 2002;(1):215-227.

14. Goodman LA. Snowball Sampling. Ann Math Stat 1961;32(1):148-170.

15. Ulin RP, Robinson TE, Tolley EE. Investigacón aplicada en salud pública: Métododos cualitativos. Washington: OMS/OPAS; 2006.

16. Hinojosa LR. La historia oral y sus aportaciones a la investigación educativa. Investig Educ la rediech 2012;3(5):57-65. 
17. Héritier F. La encuesta genealógica y el proceso de datos. In: Cresswell R, Godelier M, editors. Útiles de encuesta y análisis antropológicos. 1rst ed. Madrid, España: Fundamentos; 1981:239-284.

18. Pacheco PA. Sociología de la ciencia y semiótica. El esquema actancial en la teoría del actor-red y el programa constructivista. Redes 2013;19(36):79-103.

19. Palau H, Mesa MA, Vilella F, Contreras D. Diagnosis of hand-made cheese sector in Uruguay. VI International PENSA Conference. Brasil; 2007.

20. Krone E, Thomé CF, Menasche R. Del lomo de las mulas a la clandestinidad: Dilemas entre las exigencias legales y el sistema tradicional de producción del queso serrano de los campos de Cima da Serra (Brasil). International EAAE-SYAL Seminar-Spatial Dynamic in Agri-food Systems. Brasil; 2010.

21. Romano P, Ricciardi A, Salzano G, Suzzi G. Yeasts from Water Buffalo Mozzarella, a traditional cheese of the Mediterranean area. Int J Food Microbiol 2001;69(1-2):4551.

22. Thomé CF, Menasche R. Tradition and diversity jeopardised by food safety regulations? The Serrano Cheese case, Campos de Cima da Serra region, Brazil. Food Policy. 2014;45:116-124.

23. Villegas A, Santos A, Cervantes F. Los quesos mexicanos tradicionales. México: Universidad Autónoma Chapingo-CIESTAAM; 2016.

24. Pomeón T. El queso Cotija, México. Un producto con marca colectiva queso "Cotija Región de origen", en proceso de adquisición de una Denominación de Origen. México: FAO-IICA; 2007.

25. Poméon T. De la retórica a la práctica del patrimonio: procesos de calificación de los quesos tradicionales mexicanos [tesis doctorado]. Texcoco, México; Universidad Autónoma Chapingo; 2011.

26. Espejel GA, Rodríguez PDM, Barrera RAI, Ramírez GAG. Factores estratégicos de la innovación y mercado en queserías artesanales de México. Rev Venez Gerenc 2018;23(82):424-441.

27. Enríquez-Sánchez J, Muñoz-Rodríguez M, Altamirano-Cárdenas JR, Villegas-De Gante A. Activation process analysis of the localized agri-food system using social networks. Agric Econ 2017;63(3):121-135.

28. Guzmán M. La valorización de los alimentos en Europa y en América Latina. In: Aspects juridiques de la valorisation des denrées alimentaires Colloque Lascaux. San José, Costa Rica; 2012:1-15. 
29. Grass RJF, Sánchez GJ, Altamirano CJR. Análisis de redes en la producción de tres quesos mexicanos genuinos. Estud Sociales 2015;23(45):185-212.

30. Aguilar CE, Amaya CS, López MI. Alimentos con calidad. Nuevas estrategias rurales para nuevos consumidores. Arx d'Etnografia Catalunya 2016;(16):137-152.

31. Samardzic S, El Bilali H, Bajramovic S, Kanlic V, Ostojic A, Berjan S, et al. Cheese in a suck: exploring history, production area and production process of a typical herzegovinian product. Int J Environ Rural Dev 2014;5(2):74-79.

32. Castañeda MT, Boucher F, Sánchez VE, Espinoza OA. La concentración de agroindustrias rurales de producción de quesos en el noroeste del Estado de México: un estudio de caracterización. Estud Soc 2009;17(34):73-109.

33. Andablo RAC, Hernández MMC, Catalán DCG. Gobernanza e integración de familias rurales a cadenas pecuarias: el caso del ejido Cobachi, Sonora. Econ Teoría y Práctica. 2015;(42):105-135.

34. Lozano MO, Villegas GA. Valorización simbólica del Queso Crema de Chiapas, un queso mexicano tradicional con calidad de origen. PASOS Rev Tur y Patrim Cult 2016;14(2):459-473.

35. Goméz MMB, Armesto LXA. Productos agroalimentarios de calidad y turismo en España: Estrategias para el desarrollo local. Geographicalia 2005;(47):87-110.

36. Olivieri FM, Giraldi A. Food and wine tourism: an analysis of Italian typical products. Alma Tour 2015;(11):11-35. 